\title{
4-Methylumbelliferone inhibits enhanced hyaluronan synthesis and cell migration in pancreatic cancer cells in response to tumor-stromal interactions
}

\author{
XIAO-BO CHENG ${ }^{1}$, NORIHIRO SATO $^{2}$, SHIRO KOHI $^{2}$, ATSUHIRO KOGA $^{2}$ and KEIJI HIRATA ${ }^{2}$ \\ ${ }^{1}$ Shanghai Public Health Clinical Center, Fudan University, Shanghai 201508, P.R. China; ${ }^{2}$ Department of Surgery 1, \\ School of Medicine, University of Occupational and Environmental Health, Kitakyushu, Fukuoka 807-8555, Japan
}

Received November 18, 2015; Accepted April 25, 2017

DOI: $10.3892 / \mathrm{ol} .2018 .8147$

\begin{abstract}
Hyaluronic acid (HA) in tumor stroma promotes tumor invasion and progression. 4-Methylumbelliferone (4-MU) is a potent HA synthesis inhibitor. In the present study, the effects of 4-MU on enhanced HA synthesis and cell migration in pancreatic ductal adenocarcinoma (PDAC) cells, in response to co-culture with stromal fibroblasts, was investigated. The HA concentration was determined using ELISA and a Transwell migration assay was used to analyze cell migratory capability. The mRNA expression levels of hyaluronan synthases (HAS1, HAS2 and HAS3) were determined using the quantitative polymerase chain reaction. Co-culture between Panc-1 cells and stromal fibroblasts markedly increased cell migration in association with increasing HA production, which was markedly associated with an increase in HAS3 mRNA expression. Treatment with 4-MU markedly decreased the HA production and cell migration of Panc-1 cells in the co-culture system. The results of the present study suggested that interactions between PDAC cells and stromal fibroblasts increased HA production, resulting in a marked increase in migration of PDAC cells, and 4-MU may be used
\end{abstract}

Correspondence to: Dr Norihiro Sato, Department of Surgery 1, School of Medicine, University of Occupational and Environmental Health, 1-1, Iseigaoka, Kitakyushu, Fukuoka 807-8555, Japan

E-mail:norisato@med.uoeh-u.ac.jp

Dr Xiao-Bo Cheng, Shanghai Public Health Clinical Center, Fudan University, 2901 Caolang Road, Jin Shan, Shanghai 201508, P.R. China

E-mail: c13840564883@163.com

Abbreviations: HA, hyaluronic acid; 4-MU, 4-methylumbelliferone; PDAC, pancreatic ductal adenocarcinoma; HAS, hyaluronan synthase; dFdC, 2',2'-difluorodeoxycytidine; HMW-HA, high-molecular-weight hyaluronan; LMW-HA, low-molecular-weight hyaluronan; UGT, uridine diphosphate-glucuronyltransferase; UDP-GlcUA, uridine diphosphate-glucuronic acid

Key words: pancreatic ductal adenocarcinoma, hyaluronan, hyaluronan synthase, migration, 4-methylumbelliferone as a chemotherapeutic agent to inhibit the enhanced migration of PDAC cells in response to tumor-stromal interactions.

\section{Introduction}

Pancreatic ductal adenocarcinoma (PDAC) is a life-threatening malignant neoplasm which may invade and metastasize at an early stage (1). The deoxycytidine analogue gemcitabine [2',2'-difluorodeoxycytidine $(\mathrm{dFdC})]$ remains the standard of care for disseminated PDAC, prolonging the survival time by $>5$ weeks in a minority of patients (2). Gemcitabine-based combination therapies may offer a survival benefit by decreasing the progression of PDAC (3). A previous study has identified that targeted inhibition of the epidermal growth factor receptor with erlotinib increases the median survival time by 2 weeks (4). PDAC exhibits a poor response to chemotherapy; therefore, the identification of an effective therapy for treating advanced PDAC is required.

Hyaluronan (HA) is synthesized by three types of HA synthase (HAS) termed HAS1, HAS2 and HAS3 (5). HA is synthesized in distinct amounts and sizes, depending on the type of synthase: HAS1 and HAS2 synthesize low and high (in the range of millions of Da) amounts of high-molecular-weight HA (HMW-HA), respectively, whereas HAS3 produces high amounts of low-molecular-weight HA (LMW-HA), in the range of several thousands of $\mathrm{Da}$ (6). The size of HA may vary between $20 \mathrm{kDa}$ and $10 \mathrm{MDa}$, and, depending on the size, extracellular HA regulates a number of cellular biological functions, including cell motility, tumor viability, migration, metastasis, chemotherapeutic resistance and cytokine production, via direct interactions with cell-surface receptors (7-9). A number of human PDAC cell lines synthesize and secrete HA (10), and the highest distribution of HA between the tumor mass and the normal tissue is exhibited in human primary pancreatic carcinomas, suggesting that HA may promote tumor invasion and form a barrier for cancer cells against host immunocompetent cells and anticancer agents (11-14). A previous study revealed the association between increased expression of HA and poor prognosis in pancreatic cancer (15). Therefore, inhibiting HA synthesis to control tumor invasion and drug resistance, and subsequently to improve prognosis in patients with PDAC is required. 
4-Methylumbelliferone (4-MU; 7-hydroxy-4-methylcoumarin) has been identified to be an inhibitor of HA synthesis in a number of previous studies (16-28). In particular, the inhibitory effect of 4-MU on HA synthesis demonstrates anticancer effects through decreasing cell viability, adhesion, migration and invasion $(19,25-28)$, and increasing the efficacy of anticancer agents (23). The mechanisms that enable 4-MU to inhibit HA synthesis remain unclear. It has been hypothesized that 4-MU inhibits HA synthesis via glucuronidation by endogenous uridine phosphate (UDP)-glucuronosyltransferase (UGT), which results in the depletion of UDP-glucuronic acid (UDP-GlcUA) (20), and a decrease in HAS mRNA levels $(24,25)$. In addition, previous studies have identified that 4-MU decreases the expression of a number of matrix metalloproteinases $(29,30)$ and cell-adhesion molecules $(31)$, alters phosphorylation of intracellular proteins $(26,32,33)$ and increases levels of UGT1 enzymes, leading to decreased UDP-GlcUA levels (24).

The present study aimed at investigating whether the interaction between PDAC cells and fibroblasts may increase HA production and cell migration. Furthermore, whether 4-MU may decrease the migration of PDAC cells in co-culture with fibroblasts was investigated.

\section{Materials and methods}

Cell lines and reagents. The Panc-1 cell line was purchased from the American Type Culture Collection (Manassas, VA, USA). Primary fibroblasts derived from PDAC tissues were a gift from Kyushu University (Fukuoka, Japan). All the cell lines were maintained in RPMI-1640 medium supplemented with $10 \%$ fetal bovine serum and $1 \%$ penicillin-streptomycin (all from Thermo Fisher Scientific, Inc., Waltham, MA, USA) at $37^{\circ} \mathrm{C}$ in a humidified atmosphere containing $5 \% \mathrm{CO}_{2} .4-\mathrm{MU}$ was purchased from Sigma-Aldrich; Merck KGaA (Darmstadt, Germany).

ELISA determination of HA concentrations. HA concentrations in cell culture media were determined according to a previous protocol (15). The quantity of HA was expressed per ml.

Migration assay. Panc-1 cells $\left(2 \times 10^{5}\right.$ cells $\left./ \mathrm{ml}\right)$ in $250 \mu 1$ serum-free RPMI-1640 medium were seeded to the upper chamber (24-well insert, $8 \mu \mathrm{m}$ pore size; BD Biosciences, Franklin Lakes, NJ, USA). A total of $750 \mu 1$ serum-free RPMI-1640 medium was added to the lower chamber as a monoculture. Primary fibroblasts (ike-f3 cells) in $750 \mu 1$ serum-free RPMI-1640 medium were seeded $\left(1 \times 10^{5}\right.$ cells $\left./ \mathrm{ml}\right)$ in the lower chamber as a co-culture without or with various concentrations $(10,100$ and $1,000 \mu \mathrm{M})$ of $4-\mathrm{MU}$ for $72 \mathrm{~h}$. Additionally, $7.5 \times 10^{4}$ cells $/ \mathrm{ml}$ ike-f 3 cells were seeded in serum-free RPMI-1640 medium into the lower chamber for $72 \mathrm{~h}$ as a fibroblast monoculture. The supernatant fractions of monoculture and co-culture were divided into aliquots and stored at $-80^{\circ} \mathrm{C}$ until use. Non-migrating cells on the upper surface of the membrane were removed with a cotton swab. Migrating cells penetrated onto the lower surface of the membrane and were fixed with $70 \%$ methanol, stained with hematoxylin (at room temperature for $10 \mathrm{~min}$ ) and eosin (at room temperature, between 5-10 min) and air-dried. The

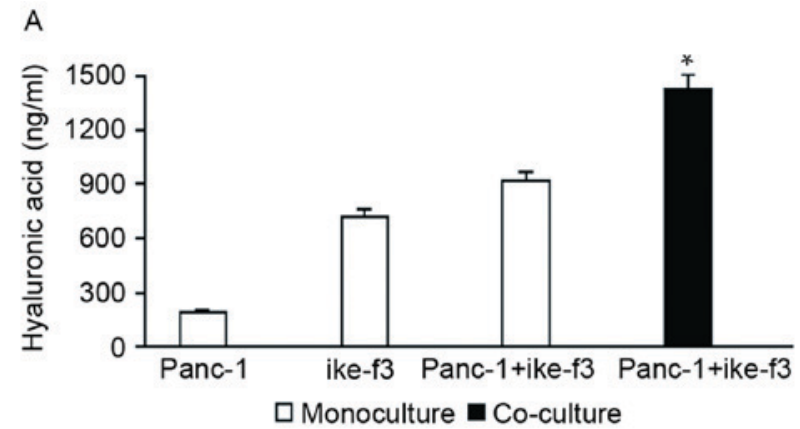

B

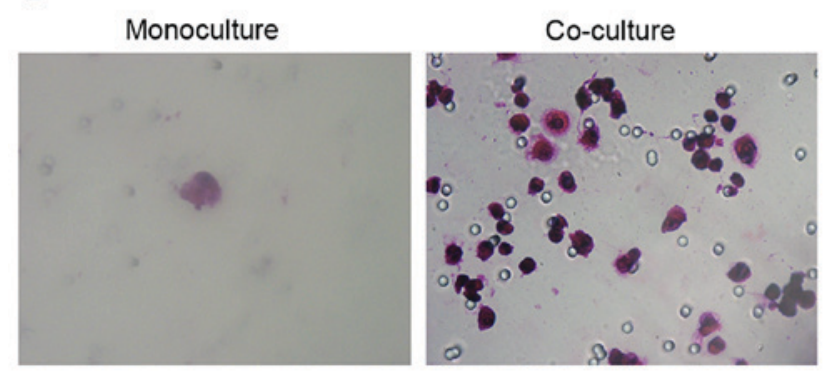

Figure 1. Alterations in HA production and pancreatic ductal adenocarcinoma cell migration in response to co-culture with fibroblasts. (A) ELISA demonstrating significantly increased HA production in co-culture system between Panc-1 cells and ike-f3 cells, compared with the sum of the incorporations by each cell line cultured alone ( $\mathrm{P}<0.05$ vs. monocultures, paired Student's $\mathrm{t}$-test). Results are presented as the mean \pm standard deviation of three replicates. (B) Transwell migration assay (magnification, x400) revealed that the co-culture system markedly increased the number of migrating Panc-1 cells. Results are presented as the mean \pm standard deviation of six replicates. HA, hyaluronan.

number of migrating cells was determined in 6 randomly selected fields at $\mathrm{x} 400$ magnification by light microscope. Subsequently, the average number of cells per microscopic field was calculated as the extent of migration.

Co-culture system. Panc- 1 cells $\left(2 \times 10^{5}\right.$ cells $\left./ \mathrm{ml}\right)$ in serum-free medium were seeded in the upper chamber (High Density, Translucent PET Membrane 6-well insert, $0.4 \mu \mathrm{m}$ pore size; BD Biosciences) and $3 \mathrm{ml}$ serum-free medium was added into the lower chamber as a monoculture. Ike-f3 cells $\left(1 \times 10^{5}\right.$ cells $\left./ \mathrm{ml}\right)$ in $3 \mathrm{ml}$ serum-free medium were seeded in the lower chamber as a co-culture for $72 \mathrm{~h}$. All samples were used to extract RNA.

Reverse transcription-quantitative polymerase chain reaction ( $R T-q P C R)$. mRNA expression analysis of $H A S I$ (Hs00758053_m1), HAS2 (Hs00193435_m1), HAS3 (Hs00193436_m1) and GAPDH (Hs02758991_g1), as a control (Applied Biosystems; Thermo Fisher Scientific, Inc.), were performed (monoculture and co-culture), according to a previously described protocol (34).

Trypan blue dye-exclusion assay cellular viability test. The effects of 4-MU (10, 100 and 1,000 $\mu \mathrm{M})$ on cell viability were analyzed using trypan blue dye-exclusion (TBDE) assays as cytotoxic measurements. After $72 \mathrm{~h}$ at $37^{\circ} \mathrm{C}$ in a humidified atmosphere containing $5 \% \mathrm{CO}_{2}$, the untreated and treated 

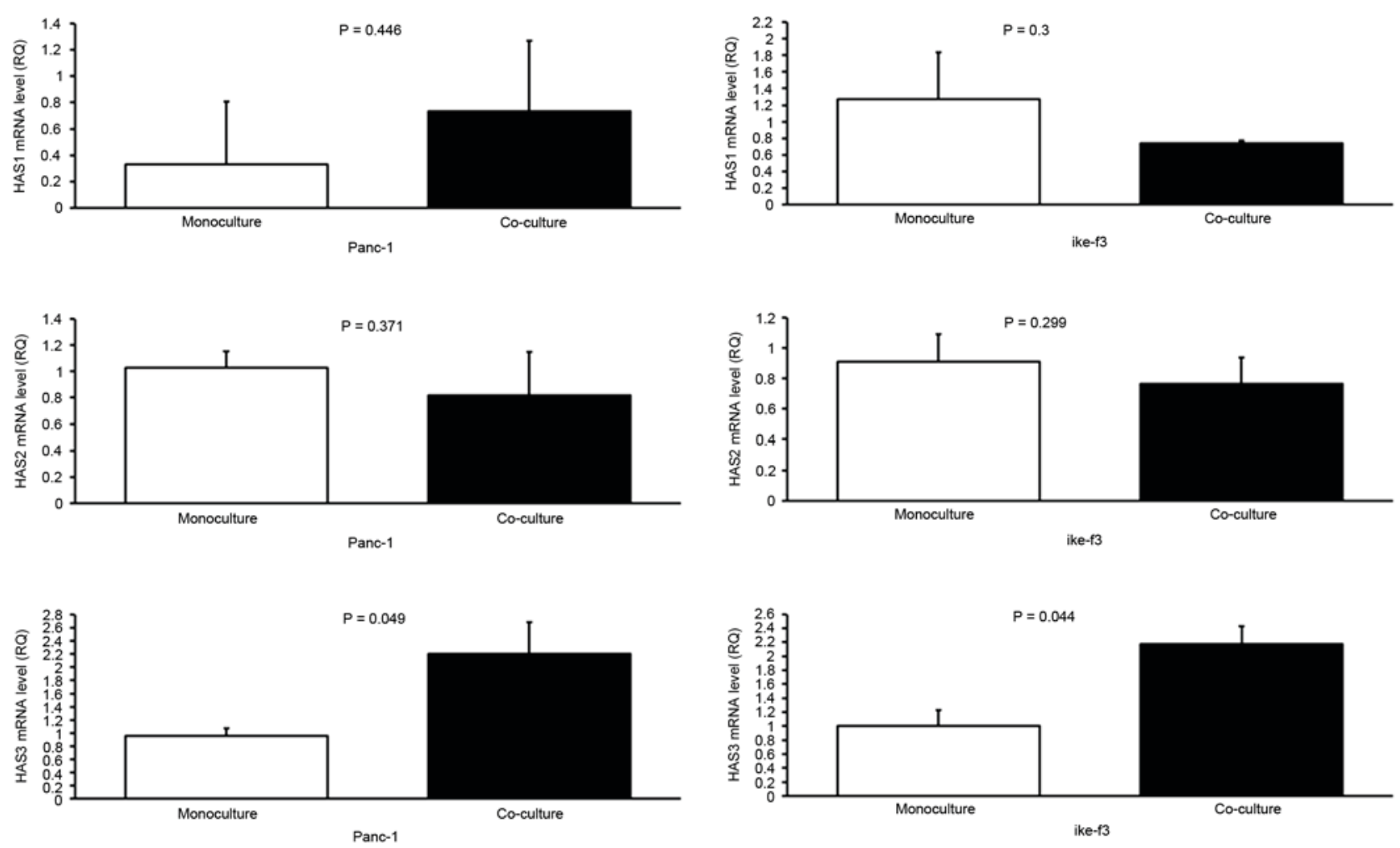

Figure 2. Alterations in HAS1, HAS2 and HAS3 mRNA expression levels in the co-culture system. HAS3 mRNA expression was significantly increased in Panc-1 cells $(\mathrm{P}=0.049)$ and ike-f3 cells $(\mathrm{P}=0.044)$, compared with monoculture. Results are presented as the mean \pm standard deviation of three replicates. HAS, hyaluronan synthase; RQ, relative quality.

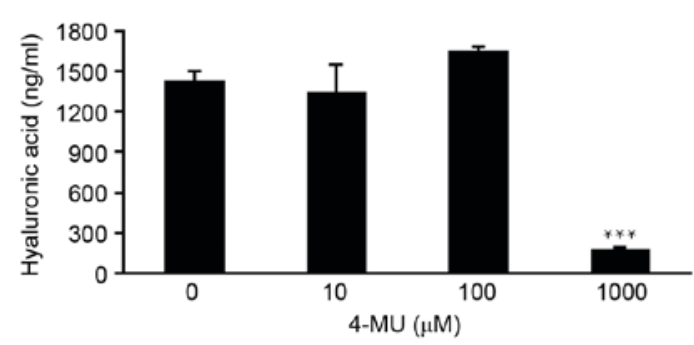

Figure 3. HA concentration in the co-culture system following treatment with 4-MU. HA synthesis was significantly decreased following treatment with 1,000 $\mu \mathrm{M} 4-\mathrm{MU}$, but was essentially unchanged at 10 and $100 \mu \mathrm{M}$ $\left({ }^{* * * *} \mathrm{P}<0.001\right.$, one-way analysis of variance and Fisher's least significant difference test). Results are presented as the mean \pm standard deviation of three replicates. HA, hyaluronan; 4-MU, 4-methylumbelliferone.

cells were harvested and stained with $4 \%$ trypan blue at room temperature and then counted by the LUNA ${ }^{\mathrm{TM}}$ automated cell counter (Logos Biosystems, Annandale, VA, USA) according to the manufacturer's protocol. Cytotoxicity was determined from the number of viable cells (no color) in treated samples as a percentage of the untreated control.

Statistical analysis. Data were expressed as the mean \pm standard deviation. All statistical analyses were performed using SPSS software (version 21.0; IBM Corp., Armonk, NY, USA). Differences in HA concentration and HAS1, HAS2 and HAS3 mRNA levels between monoculture and co-culture were compared using a paired Student's t-test. Comparisons between HA concentration and the migrating cell number, in all subgroups with various concentrations of
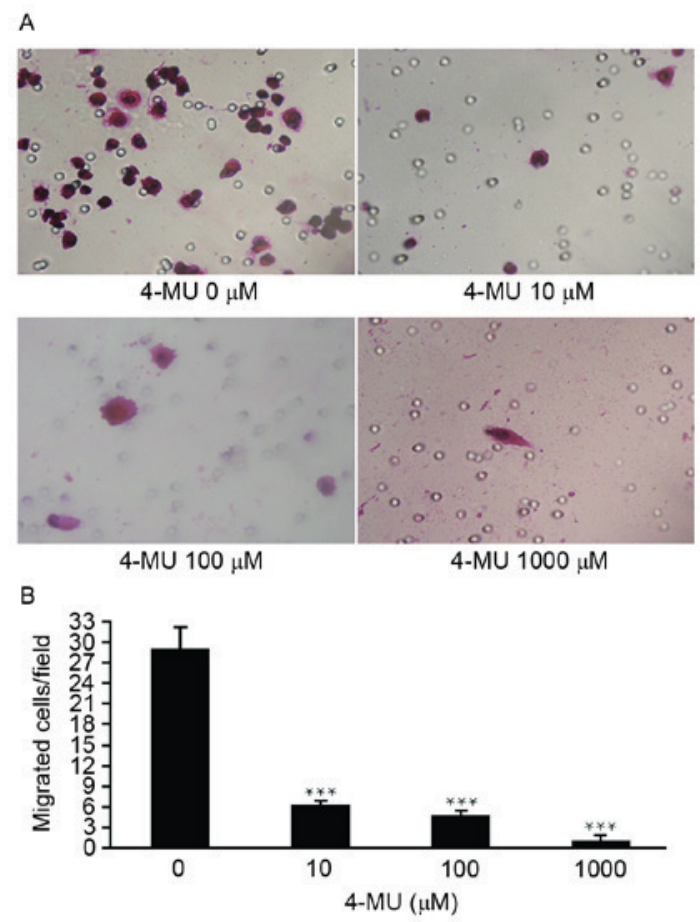

Figure 4. Alterations in the migration of pancreatic ductal adenocarcinoma cells in the co-culture system following treatment with 4-MU using a Transwell migration assay. (A) Photomicrographs of migrating cells on the underside of chambers (magnification, x400). Migrating cells penetrated onto the lower surface of the membrane and were fixed with $70 \%$ methanol, stained with hematoxylin and eosin, and air-dried. (B) Panc-1 cell migration was inhibited by $4-\mathrm{MU}$ in a dose-dependent manner $\left({ }^{* * *} \mathrm{P}<0.001\right.$, one-way analysis of variance and Fisher's least significant difference test). Results are presented as the mean \pm standard deviation of six replicates. HA, hyaluronan; 4-MU, 4-methylumbelliferone. 
4-MU, were made using one-way analysis of variance and Fisher's least significant difference test. $\mathrm{P}<0.05$ indicated a statistically significant difference. All P-values were two-tailed and all investigations were repeated three times independently.

\section{Results}

Stimulation of HA production and cell migration in the co-culture system between human PDAC cells and fibroblasts. Co-culture of Panc-1 cells with fibroblasts resulted in a significant increase $(\mathrm{P}=0.016)$ in HA production, compared with those in monocultures (Fig. 1A). In addition, the Transwell migration assay revealed that co-culture with fibroblasts significantly increased the migration of Panc-1 cells (Fig. 1B).

To elucidate the mechanism of enhanced HA production by co-culture system, the mRNA expression levels of $H A S 1$, HAS2 and HAS3 in Panc-1 cells and fibroblasts was investigated using RT-qPCR. The increased HA production was associated with a significantly increased mRNA expression of HAS3, but not HASI and HAS2 (Fig. 2).

Effects of 4-MU on HA biosynthesis and cell migration in the co-culture system. Panc-1 cells in the co-culture system were treated with various concentrations $(10,100$ and $1,000 \mu \mathrm{M})$ of 4-MU. The results demonstrated that no marked effects on the cell viability were observed following treatment with the aforementioned range of 4-MU concentrations (data not shown). HA synthesis was inhibited by $88 \%$, compared with the control, following treatment with $1,000 \mu \mathrm{M} 4-\mathrm{MU}$; however, treatment with 10 and $100 \mu \mathrm{M}$ revealed almost no alterations in HA production (Fig. 3).

Panc-1 cell migration was evaluated using a Transwell migration assay (Fig. 4A), which revealed that 4-MU inhibited Panc-1 cell migration in co-culture with fibroblasts. Inhibition of cell migration was observed at $10 \mu \mathrm{M}$ and maximal inhibition was revealed to be at $1,000 \mu \mathrm{M}$ (Fig. 4B).

\section{Discussion}

A previous study identified interactions between tumor cells and fibroblasts which stimulated HA synthesis and identified that HA is increased in tumors (35). In the present study, Panc-1 cells were co-cultured with fibroblasts which resulted in a marked increase in HA synthesis. Additionally, HAS3 mRNA expression in Panc-1 cells and fibroblasts was significantly increased in this co-culture system. The results of the present study suggested that, for the first time, to the best of our knowledge, the increase in HA in a PDAC co-culture system was associated with markedly increased mRNA expression of HAS3. HAS3 may produce increased amounts of LMW-HA (6) and this contributes to tumor progression by increasing the motility of cancer cells (36-38). These interactions may explain why the co-culture system markedly increased PDAC cell migration.

HA production may be decreased by 4-MU via the depletion of cellular UDP-GlcUA and the downregulation of HAS2 and/or HAS3, and inhibit cell viability, migration and invasiveness (25). Therefore, PDAC cells in the co-culture system were treated with 4-MU. The results revealed a marked decrease in HA production and PDAC cell migration. This drug is promising because the safety of 4-MU for humans has already been confirmed. Oral 4-MU has been used to treat hepatobiliary disease due to the cholagogic and spasmolytic actions exhibited on the sphincter of Oddi $(39,40)$. The results of the present study demonstrated that the interaction between PDAC cells and fibroblasts stimulated HA production and PDAC cell migration, and 4-MU may inhibit HA synthesis and cell migration.

\section{Acknowledgements}

The authors thank Kyushu University for providing the primary fibroblasts derived from PDAC tissues.

\section{Funding}

No funding was received.

\section{Availability of data and materials}

All data generated or analyzed during this study are included in this published article.

\section{Author's contributions}

NS, XC and $\mathrm{KH}$ conceived the experimental design. XC, SK and AK performed the experiments. XC analyzed the data. XC, NS and $\mathrm{KH}$ wrote the paper. All authors read and approved the final manuscript.

\section{Ethics approval and consent to participate}

Not applicable.

\section{Consent for publication}

Not applicable.

\section{Competing interests}

The authors declare that they have no competing interests.

\section{References}

1. Hidalgo M: Pancreatic cancer. N Engl J Med 362: 1605-1617, 2010.

2. Burris HA III, Moore MJ, Andersen J, Green MR, Rothenberg ML, Modiano MR, Cripps MC, Portenoy RK, Storniolo AM, Tarassoff P, et al: Improvements in survival and clinical benefit with gemcitabine as first-line therapy for patients with advanced pancreas cancer: A randomized trial. J Clin Oncol 15: 2403-2413, 1997.

3. Sultana A, Smith CT, Cunningham D, Starling N, Neoptolemos JP and Ghaneh P: Meta-analyses of chemotherapy for locally advanced and metastatic pancreatic cancer. J Clin Oncol 25: 2607-2615, 2007.

4. Moore MJ, Goldstein D, Hamm J, Figer A, Hecht JR, Gallinger S, Au HJ, Murawa P, Walde D, Wolff RA, et al: Erlotinib plus gemcitabine compared with gemcitabine alone in patients with advanced pancreatic cancer: A phase III trial of the national cancer institute of Canada clinical trials group. J Clin Oncol 25: 1960-1966, 2007.

5. Weigel PH and DeAngelis PL: Hyaluronan synthases: A decade-plus of novel glycosyltransferases. J Biol Chem 282: 36777-36781, 2007. 
6. Tammi RH,Passi AG, Rilla K, Karousou E, Vigetti D, Makkonen K and Tammi MI: Transcriptional and post-translational regulation of hyaluronan synthesis. FEBS J 278: 1419-1428, 2011.

7. Entwistle J, Hall CL and Turley EA: HA receptors: Regulators of signalling to the cytoskeleton. J Cell Biochem 61: 569-577, 1996

8. Adamia S, Maxwell CA and Pilarski LM: Hyaluronan and hyaluronan synthases: Potential therapeutic targets in cancer. Curr Drug Targets Cardiovasc Haematol Disord 5: 3-14, 2005.

9. Toole BP: Hyaluronan promotes the malignant phenotype. Glycobiology 12: 37R-42R, 2002.

10. Mahlbacher V, Sewing A, Elsässer HP and Kern HF: Hyaluronan is a secretory product of human pancreatic adenocarcinoma cells. Eur J Cell Biol 58: 28-34, 1992.

11. Fries H, Elsässer HP, Mahlbacher V, Neumann K and Kern HF: Localisation of hyaluronate (HA) in primary tumors and nude mouse xenografts of human pancreatic carcinomas using a biotinylated HA-binding protein. Virchows Arch 424: 7-12, 1994.

12. McBride WH and Bard JB: Hyaluronidase-sensitive halos around adherent cells. Their role in blocking lymphocyte-mediated cytolysis. J Exp Med 149: 507-515, 1979.

13. Suzuki Y, Nishida Y, Naruse T, Gemba T and Ishiguro N: Pericellular matrix formation alters the efficiency of intracellular uptake of oligonucleotides in osteosarcoma cells. J Surg Res 152: 148-156, 2009.

14. Toole BP: Hyaluronan-CD44 interactions in cancer: Paradoxes and possibilities. Clin Cancer Res 15: 7462-7468, 2009.

15. Cheng XB, Sato N, Kohi S and Yamaguchi K: Prognostic impact of hyaluronan and its regulators in pancreatic ductal adenocarcinoma. PLoS One 8: e80765, 2013.

16. Nakamura T, Takagaki K, Shibata S, Tanaka K, Higuchi T and Endo M: Hyaluronic-acid-deficient extracellular matrix induced by addition of 4-methylumbelliferone to the medium of cultured human skin fibroblasts. Biochem Biophys Res Commun 208 470-475, 1995.

17. Nakamura T, Funahashi M, Takagaki K, Munakata H, Tanaka K, Saito Y and Endo M: Effect of 4-methylumbelliferone on cell-free synthesis of hyaluronic acid. Biochem Mol Biol Int 43: 263-268, 1997.

18. Kakizaki I, Takagaki K, Endo Y, Kudo D, Ikeya H, Miyoshi T, Baggenstoss BA, Tlapak-Simmons VL, Kumari K, Nakane A, et al: Inhibition of hyaluronan synthesis in Streptococcus equi FM100 by 4-methylumbelliferone. Eur J Biochem 269: 5066-5075, 2002

19. Kudo D, Kon A, Yoshihara S, Kakizaki I, Sasaki M, Endo M and Takagaki K: Effect of a hyaluronan synthase suppressor, 4-methylumbelliferone, on B16F-10 melanoma cell adhesion and locomotion. Biochem Biophys Res Commun 321: 783-787, 2004.

20. Kakizaki I, Kojima K, Takagaki K, Endo M, Kannagi R, Ito M, Maruo Y, Sato H, Yasuda T, Mita S, et al: A novel mechanism for the inhibition of hyaluronan biosynthesis by 4-methylumbelliferone. J Biol Chem 279: 33281-33289, 2004.

21. Yoshihara S, Kon A, Kudo D, Nakazawa H, Kakizaki I, Sasaki M, Endo $\mathrm{M}$ and Takagaki K: A hyaluronan synthase suppressor, 4-methylumbelliferone, inhibits liver metastasis of melanoma cells. FEBS Lett 579: 2722-2726, 2005.

22. Morohashi H, Kon A, Nakai M, Yamaguchi M, Kakizaki I, Yoshihara S, Sasaki M and Takagaki K: Study of hyaluronan synthase inhibitor, 4-methylumbelliferone derivatives on human pancreatic cancer cell (KP1-NL). Biochem Biophys Res Commun 345: 1454-1459, 2006.

23. Nakazawa H, Yoshihara S, Kudo D, Morohashi H, Kakizaki I, Kon A, Takagaki K and Sasaki M: 4-methylumbelliferone, a hyaluronan synthase suppressor, enhances the anticancer activity of gemcitabine in human pancreatic cancer cells. Cancer Chemother Pharmacol 57: 165-170, 2006.

24. Vigetti D, Rizzi M, Viola M, Karousou E, Genasetti A, Clerici M, Bartolini B, Hascall VC, De Luca G and Passi A: The effects of 4-methylumbelliferone on hyaluronan synthesis, MMP2 activity, proliferation, and motility of human aortic smooth muscle cells. Glycobiology 19: 537-546, 2009.

25. Kultti A, Pasonen-Seppänen S, Jauhiainen M, Rilla KJ, Kärnä R, Pyöriä E, Tammi RH and Tammi MI 4-Methylumbelliferone inhibits hyaluronan synthesis by depletion of cellular UDP-glucuronic acid and downregulation of hyaluronan synthase 2 and 3. Exp Cell Res 315: 1914-1923, 2009.
26. Lokeshwar VB, Lopez LE, Munoz D, Chi A, Shirodkar SP, Lokeshwar SD, Escudero DO, Dhir N and Altman N: Antitumor activity of hyaluronic acid synthesis inhibitor 4-methylumbelliferone in prostate cancer cells. Cancer Res 70: 2613-2623, 2010.

27. Twarock S, Freudenberger T, Poscher E, Dai G, Jannasch K, Dullin C, Alves F, Prenzel K, Knoefel WT, Stoecklein NH, et al: Inhibition of oesophageal squamous cell carcinoma progression by in vivo targeting of hyaluronan synthesis. Mol Cancer 10: 30 , 2011.

28. Urakawa H, Nishida Y, Wasa J, Arai E, Zhuo L, Kimata K, Kozawa E, Futamura N and Ishiguro N: Inhibition of hyaluronan synthesis in breast cancer cells by 4 -methylumbelliferone suppresses tumorigenicity in vitro and metastatic lesions of bone in vivo. Int J Cancer 130: 454-466, 2012.

29. Nakamura R, Kuwabara H, Yoneda M, Yoshihara S, Ishikawa T, Miura T, Nozaka H, Nanashima N, Sato T and Nakamura T: Suppression of matrix metalloproteinase- 9 by 4-methylumbelliferone. Cell Biol Int 31: 1022-1026, 2007.

30. Nakamura T, Ishikawa T, Nanashima N, Miura T, Nozaka H, Nakaoka $\mathrm{R}$ and Sato T: 4-Methylumbelliferone induces the expression of membrane type 1-matrix metalloproteinase in cultured human skin fibroblasts. Biochem Biophys Res Commun 298: 646-650, 2002.

31. Kuwabara H, Yoneda M, Hayasaki H, Nakamura $T$ and Shibayama Y: A hyaluronan synthase suppressor, 4-methylumbelliferone, inhibits the tumor invasion associated with N-cadherin decreasement. Pathol Int 61: 262-263, 2011.

32. Svensson Holm AC, Bengtsson T, Grenegård $M$ and Lindström EG: Hyaluronic acid influence on platelet-induced airway smooth muscle cell proliferation. Exp Cell Res 318: 632-640, 2012

33. Twarock S, Tammi MI, Savani RC and Fischer JW: Hyaluronan stabilizes focal adhesions, filopodia, and the proliferative phenotype in esophageal squamous carcinoma cells. J Biol Chem 285: 23276-23284, 2010.

34. Cheng XB, Sato N, Kohi S, Koga A and Hirata K: Receptor for hyaluronic acid-mediated motility is associated with poor survival in pancreatic ductal adenocarcinoma. J Cancer 6: 1093-1098, 2015

35. Knudson W, Biswas C and Toole BP: Interactions between human tumor cells and fibroblasts stimulate hyaluronate synthesis. Proc Natl Acad Sci USA 81: 6767-6771, 1984.

36. Sugahara KN, Murai T, Nishinakamura H, Kawashima $H$, Saya $\mathrm{H}$ and Miyasaka M: Hyaluronan oligosaccharides induce CD44 cleavage and promote cell migration in CD44-expressing tumor cells. J Biol Chem 278: 32259-32265, 2003.

37. Wu M, Cao M, He Y, Liu Y, Yang C, Du Y, Wang W and Gao F. A novel role of low molecular weight hyaluronan in breast cancer metastasis. FASEB J 29: 1290-1298, 2015.

38. Schmaus A, Klusmeier S, Rothley M, Dimmler A, Sipos B, Faller G, Thiele W, Allgayer H, Hohenberger P, Post S and Sleeman JP: Accumulation of small hyaluronan oligosaccharides in tumour interstitial fluid correlates with lymphatic invasion and lymph node metastasis. Br J Cancer 111: 559-567, 2014.

39. Fontaine L, Grand M, Molho D and Boschetti E: Spasmolytic activity of 4-methylumbelliferone on Oddi's sphincter. Studies on the mode of action of the drug. Therapie 23: 63-74, 1968 (In French).

40. Fontaine L, Grand M, Molho D, Chabert MJ and Boschetti E: Choleretic, spasmolytic and general pharmacologic activities of 4-methylumbelliferone. Therapie 23: 51-62, 1968 (In French).

This work is licensed under a Creative Commons Attribution-NonCommercial-NoDerivatives 4.0 International (CC BY-NC-ND 4.0) License. 